\title{
Pulsed and Tissue Doppler Echocardiographic Abnormalities in Patients with Diastolic Heart Failure with and without Atrial Fibrillation
}

\author{
Taysir Said Garadah ${ }^{1,2}$, Najat Hassan Mahdi ${ }^{1,2}$, Mohamed Ahmed Al Alwai ${ }^{1}$, \\ Ahmed Abdulkareem Jaradat, Zuheir Ahmed Hasan ${ }^{2}$ \\ ${ }^{1}$ Salmaniya Medical Complex, Ministry of Health, Manama, Bahrain; ${ }^{2}$ College of Medicine and Medical Sciences, Arabian Gulf \\ University, Manama, Bahrain. \\ Email: garadaht@hotmail.com
}

Received September $11^{\text {th }}, 2012$; revised October $20^{\text {th }}, 2012$; accepted November $9^{\text {th }}, 2012$

\begin{abstract}
Background: Symptoms of heart failure (HF) are identical in both systolic (SHF) and diastolic hear failure (DHF). The prevalence of atrial fibrillation (AF) in heart failure varies in different studies depending on the criteria of enrollment and the use of echocardiographic parameters in the definition of HF. Aim: To assess the clinical characteristic of patients with DHF complicated by AF and compare with those with SHF in regard of echocardiographic abnormalities and causative agents. Furthermore, evaluate the clinical and biochemical markers for the prediction of AF in HF. Method: Over the duration of 12 months, each patient diagnosed as HF based on admission code was enrolled in the study. Patients were classified into two groups: group 1: DHF, with preserved LVPEF\% $>50 \%, \mathrm{n}=204$ (60\%), and group 2, with SHF, with LVREF\% $\leq 50 \%, \mathrm{n}=140(40 \%)$. The presence or absence of AF on ECG was recorded. The predictive value of different clinical and biochemical variables for the development of AF was evaluated using logistic multiple regression analysis. Results: Three hundred and forty four eligible patients were admitted to hospital with heart failure out of 7650 who had other medical problems. The prevalence of HF in this population was $4.5 \%$, those with DHF were $2.7 \%$ and SHF of $1.8 \%$. The incidence of AF on ECG was 35\% in the whole study population and $65 \%$ were in sinus rhythm (SR). The occurrence of AF was twice higher in DHF patients of $22 \%$ compared with $11 \%$ in SHF. Echo pulsed Doppler in DHF and AF compared with those in SR showed a severe restrictive pattern with significantly thick septum wall, higher LV mass index, shorter DT and higher E/e ratio of 12.4 vs. $9.73, \mathrm{P}<0.05$. The predictive risk (odd ratio) of different clinical variables for development of AF in HF was positive for LV hypertrophy on ECG of 2.4, history of hypertension of 1.6, history of DM of 1.4, BMI > 28 of 1.7. Conclusions: The prevalence of HF was $4.5 \%$ in the study population, with SHF of $1.8 \%$ and DHF of $2.7 \%$. Patients with DHF and AF were older with a higher female ratio with severe restrictive pattern compared with those of SHF. The incidence of AF in the whole study was $35 \%$. The best predictor of AF in HF was left ventricle hypertrophy followed by history of hypertension and DM.
\end{abstract}

Keywords: Diastolic Heart Failure; Atrial Fibrillation; Tissue Doppler; Bahrain

\section{Introduction}

The symptoms of heart failure (HF) may be identical whether failure is secondary to systolic dysfunction (SHF) with reduction of left ventricle (LV) systolic function or diastolic heart failure (DHF) with normal LV function. In patients with SHF the left ventricle (LV) is dilated and LV ejection fraction on echocardiogram of $\leq 50 \%$.

DHF had normal LV cavity dimensions with no valve disease and LVEF $>50 \%$, [1] but abnormal echo indices of left ventricle diastolic filling such as abnormal relaxation and or dispensability (restriction) of the LV [2]. DHF accounts for $30 \%-50 \%$ of patients with heart fail- ure and is an independent predictor of atrial fibrillation in the elderly [3]. Heart failure is a recognized risk factor for atrial fibrillation (AF) as a coexistent complication [4].

The overall prevalence of new onset of AF in patients hospitalized for $\mathrm{HF}$ is in the range of $8 \%-36 \%$ [5]. It has been observed that the incidence of AF is increasing as the severity of HF is increases, $10 \%-20 \%$ of AF occurs in patients with mild to moderate $\mathrm{HF}$ and up to $50 \%$ in patients with severe disease [6]. Patients with DHF shown to have higher prevalence of AF than those with SHF [7]. Previous reports showed that the occurrence of AF increased in patients with HF and is of a deleterious impact with poor clinical outcomes in terms of mortality 
and hospitalization $[8,9]$.

Randomized pathophysiologic studies showed important differences between patients with systolic heart failure (SHF) and diastolic heart failure (DHF) as the two conditions were suggested to be distinct syndromes rather than a continuous spectrum of one disorder [10, 11]. The difference between both type of heart failure in clinical and histopathological levels indicates that they are distinct phenotypes $[12,13]$.

Brain natriuretic peptide (BNP), a cardiac neurohormone, had been recognized as a marker of HF usually released by the left ventricle in response to volume expansion and pressure overload [14]. BNP had been shown earlier to be sensitive biomarkers for the detection of a symptomatic LV dysfunction and that they had important diagnostic and prognostic implications in patients with LV dysfunction [15].

To date, studies on the relationship between HF with DHF and the development of AF in nonwhite population are limited.

In this study we aim to first: to assess the incidence of AF in patients with DHF and compare with those with SHF in regard of clinical characteristics, causative agents and echo abnormalities. Second: to evaluate the clinical and biochemical markers of for the prediction of $\mathrm{AF}$ in $\mathrm{HF}$.

\section{Material and Methods}

Patients admitted to the Salmaniya hospital with diagnosis of acute heart failure, based on hospital admission code, were included and clinical data was extracted from patient's files. The study duration was of 12 months from 1.1.2010 to 31.12.2010.

Salmaniya hospital is the main governmental hospital with a catchment area of 900,000 populations. There were 344 patients that had heart failure based on admission code. The Total number of patients who were admitted with acute medical problems for the same duration was 7650 patients.

Patient's data regarding clinical history and physical findings on examination, biochemical laboratory results were obtained. The results of echocardiography and electrocardiographic data were available for all patients on admission or during hospital stay.

A constitutional ethical committee approval was obtained prior to the data extraction and analysis.

\subsection{Inclusion Criteria}

Subjects were included if they were presented with acute dyspnea and clinical diagnosis of HF by code of admission. The history of dyspnea class was obtained based on New York Heart Association (NYHA) functional classification [16].

\subsection{Clinical Assessment}

The clinical findings on examination of S3 gallop and bibasal crackle and raised jugular venous pressure, heaptomegaly and ankle edema were all recorded. Patients were labeled as biventricular failure if both left and right HF signs are present clinically.

Clinical demographic data and past medical history of heart failure, history of hypertension and diabetes mellitus (DM) prior to admission, history of smoking and previous documentation of AF were extracted from the patients file.

Twelve leads ECG was evaluated for the presence of voltage criteria of left ventricle hypertrophy using Perugia score [17].

The presence of Q wave and conduction abnormality with ST segment elevation or depression or $\mathrm{T}$ wave changes ware all recorded. Atrial fibrillation was defined as absence of $\mathrm{P}$ wave on 12 leads electrocardiogram (ECG), with irregular ventricular rhythm and last for $>30$ seconds [18].

Echocardiographic data of M mode, 2 D. Pulsed and tissue doppler were tabulated for the dimension of LV cavity dimensions, wall thickness on $\mathrm{M}$ mode and calculated LV mass index, the calculated left ventricle ejection fraction (LVEF\%), valve abnormalities and indices of left ventricle diastolic fillings were tabulated [19].

Patients were subdivided into those with preserved LVPFE $\%>50 \%$ and reduced LVREF $\%$ of $\leq 50 \%$. Those with LVREF $\% \leq 50 \%$ patients were grouped based on calculation of $\mathrm{EF} \%$ using $\mathrm{M}$ mode, Teichholz formula as very mild (LVREF $\%<43 \%-\geq 50 \%$ ), mild (LVREF of $<33 \%-\geq 43 \%)$, moderate $(<23 \%-\geq 33 \%)$ and severe $(<22 \%)$ [20,21].

The diastolic indices and the severity of diastolic dysfunction based on E/A ratio, deceleration time (DT) of E wave and $\mathrm{E} / \mathrm{e}^{-}$was assessed in all patient as mild, moderate or severe if the $\mathrm{E} / \mathrm{A}$ ratio is $\mathrm{E} / \mathrm{A}<1,1-2$ and $\geq 2$ respectively [22]. Estimated LV mass index on echo of $>131 \mathrm{~g} / \mathrm{m}^{2}$ ) for men and $>113 \mathrm{~g} / \mathrm{m}^{2}$ for women was defined as cut off points for severe LVH [23].

Heart failure was documented as a clinical diagnosis in 344 patients. The total number of patients who were admitted to emergency room with acute medical disease was 7650 . There were $120(35 \%)$ patients who had AF on 12 leads ECG and $224(60 \%)$ were in sinus rhythm (SR). The study population was subdivided based on LVEF\% into group 1, patients with DHF with LVPEF > $50 \%, \mathrm{n}=204(60 \%)$ and group 2, with SHF and LVREF $\leq 50 \%, \mathrm{n}=140$.

\subsection{Clinical History}

Patient's age, gender, history of rheumatic fever in child- 
hood, history hypertension and alcohol intake were all recoded. The clinical presentation on admission such as fast palpitation, angina pectoris pain, dyspnea, dizziness, and focal neurological deficit were recorded. The NYHA class of I to IV on admission was also recorded.

The height and weight, the presence or absence of goiter, cardiac murmur suggestive of aortic or mitral or pulmonary valve disease was all recorded. The signs of pulmonary edema such as bibasal crackles and gallop, elevated JVP, ankle odema were recorded.

The results of available serum level of brain natriuretic peptide (BNP), uric acid, estimated Glomerular Filtration Rate (eGFR) and serum potassium were tabulated.

\subsection{Statistical Analysis}

All data were entered and analyzed using the Statistical Package of Social Sciences (SPSS) version 17.1. Data are presented as mean $\pm \mathrm{SD}$. Unpaired student-test was used to analyze the differences between the mean variables of M mode for septal wall thickness, LV cavity and LV mass index in the two groups.

Student's t-test was applied for continuous variables and Chi-square analysis for frequency non-continuous data such as Doppler ratio for pulsed derived indices of $\mathrm{E}$ wave to A wave velocity (E/A) ratio, deceleration time (DT) of E wave and pulsed to tissue derived Doppler ratio of $\mathrm{E}$ wave velocity $\left(\mathrm{E} / \mathrm{e}^{-}\right)$.

Multiple logistic regression analysis was used to calculate the odds ratio for different clinical and biochemical variables for the development of AF in the study group. Clinical variables are the history of hypertension, DM, smoking, body mass index, LV hypertrophy on ECG and the biochemical variables are serum level of uric acid, potassium level, BNP and eGFR.

All reported P-values are two tailed and P-value was regarded as significant at level of $<0.05$.

\section{Results}

Three hundred and forty four patients with clinical diagnosis of heart failure were enrolled and divided into two groups based on LVEF\% on echo: group 1, diastolic heart failure with preserved systolic LV-PEF, $\mathrm{n}=204$ $(60 \%)$ and group 2, with SHF and reduced systolic function LV-REF, $\leq 50 \%, \mathrm{n}=140(40 \%)$.

Patients with DHF were older than SHF, mean age of $64.4 \pm 12$ and $55.9 \pm 15$ respectively. In the whole study there were 195 females and 150 males. Sixty five percent of patients were female gender DHF patients and there were $52 \%$ in those with SHF. Table 1 shows the clinical characteristic of patients in both groups.

Patients with DHF compared with SHF had signifycantly a higher number of patients with history of hypertension of $34 \%$ vs. 8 , DM of $25 \%$ vs. $14 \%$, history of smoking of $23 \%$ vs. $17 \%$ and BMI $>28$ of $14 \%$ vs. $10 \%$ and history of hyperlipidemia of $104(30 \%)$ vs. 42 (12\%). Those with history of myocardial ischemia were of no significant difference in both groups.

\subsection{ECG}

The total number of patients who had atrial fibrillation on admission were $120(35 \%)$ and $223(65 \%)$ were in sinus rhythm. In the whole study out of those who had AF $(35 \%)$, the new onset AF with no previous history of AF was detected in $72(21 \%)$ patients and $48(14 \%)$ patients had history of chronic AF.

Patients with left ventricle hypertrophy based on ECG criteria were $160(46 \%)$. Among those with LVH there were $89(26 \%)$ patients with $\mathrm{AF}$ and $71(21 \%)$ were in sinus rhythm. The overall sensitivity and specificity of

Table 1. Demographic data of all patients who were admitted with heart failure $(n=344)$.

\begin{tabular}{|c|c|c|c|c|}
\hline Character & $\begin{array}{c}\text { Total } \\
N=344\end{array}$ & $\begin{array}{c}\text { LV-PEF (DHF) } \\
\mathrm{N}=204(60 \%)\end{array}$ & $\begin{array}{c}\text { LV-REF (SHF) } \\
\mathrm{N}=140(40 \%)\end{array}$ & P value \\
\hline Age in years & $68.6 \mp 16$ & $64.4 \mp 12$ & $55.9 \mp 15$ & 0.035 \\
\hline Female gender & $188(54 \%)$ & $115(56 \%)$ & $73(52 \%)$ & 0.047 \\
\hline History of hypertension & $128(37 \%)$ & $104(30 \%)$ & $24(7 \%)$ & 0.016 \\
\hline History of myocardial ischemia & $65(19 \%)$ & $30(9 \%)$ & $35(10 \%)$ & 0.082 \\
\hline History of DM & $118(34 \%)$ & $76(22 \%)$ & $42(12 \%)$ & 0.036 \\
\hline History of smoking & $119(40 \%)$ & $68(20 \%)$ & $51(15 \%)$ & 0.041 \\
\hline $\mathrm{BMI}>28$ & $71(20 \%)$ & $40(11 \%)$ & $31(9 \%)$ & 0.045 \\
\hline History of hyperlipidemia & $147(48 \%)$ & $105(30 \%)$ & $42(12 \%)$ & 0.019 \\
\hline
\end{tabular}

Abbreviation: LV-PEF: left ventricle with preserved ejection fraction; LV-REF: left ventricle with reduced ejection fraction; DHF: diastolic heart failure; SHF: systolic heart failure; BMI: body mass index; DM: diabetes mellitus. 
ECG for detection of LVH compared with BMI derived by echo as gold standard $75 \%$ and $60 \%$ respectively.

\subsection{Clinical Findings}

All patients had heart failure on admission, 154 (45\%) patients had left ventricle failure manifested with pulmonary odema and 120 (35\%) had both left ventricular and right ventricular failure (biventricular). There were 20 patients in NYHA functional class IV, 114 were in class III, 210 patients were in functional class II and none was in class I. History of medication on prior to admission showed $270(78 \%)$ patients were taking angiotensin receptor antagonist (ACE) tablet, $198(57 \%)$ were on diuretics, $125(36 \%)$ on beta blocker, and $58(17 \%)$ were on digoxin medication.

\subsection{Heart Failure and Patient's Age}

Figure 1 show patients age distribution for both groups. In the age category of 20 - 35 years, patients with DHF had the ratio of 1.9 higher than SHF, for category of (35$50)$ the ratio was 1.6 , for age category of $(50-65)$ years it was 2 , and in age category of $>65$ years the ratio was nearly equal of 0.96 for both types of HF.

\subsection{Echocardiographic and Biochemical Variables}

There were 204 (60\%) patients who had DHF and 140 (40\%) were with SHF. Table 2 shows biochemical, Pulsed and tissue Doppler results in both groups. In those with DHF and AF on ECG compared with those with SR, $M$ mode echocardiogram showed significantly thicker septal and posterior wall of LV. The LV mass index was significantly higher of 112.1 vs. $104.9 \mathrm{gm} / \mathrm{m}^{2}$. Further, Pulsed Doppler showed significantly higher E/A ratio of $1.42 \pm 0.31$ vs. $0.81 \pm 0.2 .5$ lower DT $200 \mp 15.3 \mathrm{~m} \mathrm{sec}$ vs. $233.5 \pm 20.1 \mathrm{~m}$ sec suggesting restrictive pattern. The tissue Doppler showed higher E/ $\mathrm{e}^{-}$ratio of $12.41 \mp 3.5 \mathrm{vs}$. $9.73 \pm 2.5$.

In SHF and AF on ECG compared with S R, M mode Echo showed no significant difference in wall thickness but of LV septal and posterior wall but LV cavity showed significant dilation of LV cavity in both systole and diastole. Pulse and Tissue Doppler showed significantly higher E/A ratio, shorter DT and higher E/ $\mathrm{e}^{-}$. The LV mass index was lower but the difference was of no significant.

\subsection{Biochemical Markers}

In DHF Blood chemistry in patients with $\mathrm{AF}$ showed significantly higher level of uric acid, BNP and lower potassium level, however difference between eGFR was

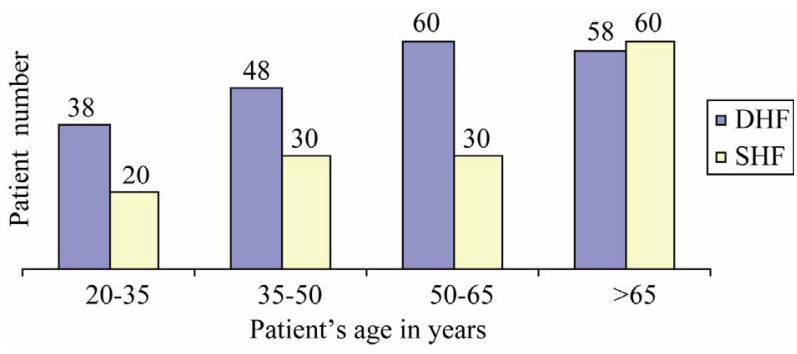

Figure 1. Distribution of patients of both groups in HF according to patients age, patients with DHF (LV-PEF), $n=$ 204) and those with SHF (LV-REF), $n=140$.

of no significance. In SHF patients and AF compared with those of SR, there significantly higher level of uric acid, higher eGFR and BNP but difference of potassium level was not significant.

Segmental wall motion abnormality was detected in DHF and AF in $32(9 \%)$ patients versus $14(4 \%)$ in those with SR. In SHF and AF those with segmental wall motion abnormality were detected in 4 (12\%) patients versus $24(7 \%)$ in those with SR. Figure 2 shows the distribution of patients with AF and SR in both groups. In DHF the ratio between those with AF to SR was 0.51 and in SHF it was 0.6.

Medication prior to admission showed 270 (78\%) patients using angiotensin receptor antagonist (ACE) tablet, $198(57 \%)$ were on diuretics, $125(36 \%)$ on Beta blocker, and $58(17 \%)$ were on digoxin tablet.

\subsection{Etiological Diagnosis}

The etiology in DHF, $\mathrm{n}=204$, showed 74 (36\%) patients in hypertensive emergency with systolic $\mathrm{BP}>180 \mathrm{mmHg}$ complicated with pulmonary edema. Seventy (34\%) patients had ischemic heart disease, among them 39 had acute myocardial infarction and 31 had unstable angina. Ten $(5 \%)$ patients had thyrotoxicosis, $10(5 \%)$ had history suggestive of Dilated Myopathy, 10 patients had valve disease (5\%), seven had severe mitral regurgitation and three with moderate to severe aortic regurgitation. There were thirty $(15 \%)$ patients with no definite etiological diagnosis.

In SHF, $\mathrm{n}=140$. There were $45(32 \%)$ patients with dilated cardiomyopathy, nine (9\%) had hypertension heart failure, 30 (21\%) had ischemic heart disease), 27 $(19 \%)$ had significant valve disease with 16 of mitral valve regurgitation and 11 had severe aortic regurgitation, $13(9 \%)$ patients had thyroid disease and $15(10 \%)$ were of unknown etiology.

\subsection{The Odds Ratio for Risk of $\mathrm{AF}$ in $\mathrm{HF}$ Patients}

Table 3 shows the hazard ratio of different variables in 
Table 2. The mean value $\mp$ standard deviation (SD) of biochemical markers and echocardiographic indices in all patients presented with $\mathrm{HF}, \mathrm{n}=344$.

\begin{tabular}{|c|c|c|c|c|c|c|}
\hline \multirow{2}{*}{ ECG } & \multicolumn{3}{|c|}{ LVPEF $>50 \%$, (DHF) Group $1 \mathrm{~N}=204$} & \multicolumn{3}{|c|}{ LVREF $\leq 50 \%$, (SHF) Group $2 N=140$} \\
\hline & $\begin{array}{c}\mathrm{AF} \\
\mathrm{N}=76\end{array}$ & $\begin{array}{c}\mathrm{SR} \\
\mathrm{N}=128\end{array}$ & $P$ value & $\begin{array}{c}\mathrm{AF} \\
\mathrm{N}=45\end{array}$ & $\begin{array}{c}\text { SR } \\
\mathrm{N}=95\end{array}$ & $P$ value \\
\hline IVS cm & $1.18 \mp 0.12$ & $1.03 \pm 0.24$ & 0.001 & $0.98 \pm 0.15$ & $0.97 \pm 0.17$ & 0.072 \\
\hline $\mathrm{PW} \mathrm{cm}$ & $1.14 \mp 0.21$ & $0.91 \pm 0.16$ & 0.01 & $0.89 \pm 0.24$ & $0.86 \pm 0.21$ & 0.081 \\
\hline $\mathrm{ESD} \mathrm{cm}$ & $3.79 \mp 0.23$ & $3.94 \pm 0.29$ & 0.06 & $5.73 \pm 0.25$ & $5.21 \pm 0.13$ & 0.021 \\
\hline EDD cm & $5.43 \mp 0.32$ & $5.51 \pm 0.24$ & 0.076 & $6.82 \pm 0.32$ & $6.73 \pm 0.27$ & 0.043 \\
\hline LV Mass Index & $112.1 \mp 0.53$ & $104.9 \pm 5.34$ & 0.032 & $111.7 \pm 3.9$ & $112.9 \pm 3.7$ & 0.065 \\
\hline DT msc & $200.1 \mp 15.3$ & $233.5 \pm 20.1$ & 0.046 & $163.5 \pm 19.3$ & $214 . \pm 20.4$ & 0.001 \\
\hline $\mathrm{E} / \mathrm{A}$ ratio & $1.42 \pm 0.31$ & $0.81 \pm 0.36$ & 0.001 & $1.7 \pm 0.24$ & $1.3 \pm 0.21$ & 0.032 \\
\hline $\mathrm{E} / \mathrm{e}^{-}$ratio & $12.41 \pm 3.5$ & $9.73 \pm 2.5$ & 0.04 & $14.2 \pm 3.5$ & $10.1 \pm 4.9$ & 0.024 \\
\hline $\mathrm{BNP}$ in $(\mathrm{pg} / \mathrm{ml})$ & $465 \pm 56.8$ & $350 \mp 70.4$ & 0.035 & $728 \pm 89.2$ & $689 \pm 76.2$ & 0.026 \\
\hline Uric acid $\mathrm{mmol} / \mathrm{L}$ & $421.12 \pm 48.3$ & $388.23 \pm 47.4$ & 0.031 & $456.9 \pm 67.4$ & $386.8 \pm 56.9$ & 0.036 \\
\hline eGFR & $83.2 \pm 7.3$ & $86.1 \pm 8.3$ & 0.082 & $89.5 \pm 9.3$ & $56.7 \pm 8.7$ & 0.001 \\
\hline Potassium mmol/L & $3.27 \pm 1.3$ & $3.95 \pm 0.7$ & 0.012 & $3.9 \pm 0.37$ & $4.02 \pm 0.41$ & 0.064 \\
\hline
\end{tabular}

Abbreviations: diastolic heart failure (DHF); systolic heart failure (SHF); interventricular septum (IVS); posterior wall (PW); end systolic dimension (ESD); end diastolic dimension (EDD); deceleration time (DT); estimated glomerular filtration rate (eGFR); atrial fibrillation (AF); sinus rhythm (SR) (ratio of E velocity to tissue doppler velocity of septum $\left(\mathrm{E} / \mathrm{e}^{-}\right)$.

Table 3. The hazard ratio for the development for $\mathrm{AF}$ in patients presented with heart failure using logistic multiple regression analysis in patients presented with heart failure, $\mathrm{n}=344$.

\begin{tabular}{cccc}
\hline Variable & Odds ratio & Confidence interval & P value \\
\hline $\begin{array}{c}\text { History of } \\
\text { hypertension }\end{array}$ & 1.6 & (CI 95\%: $1.1-2.1)$ & 0.036 \\
$\begin{array}{c}\text { History of DM } \\
\text { History of smoking }\end{array}$ & 1.4 & (CI 95\%: 0.7 - 2.25) & 0.037 \\
$\quad$ BMI $>28$ & 1.7 & (CI 95\%: $0.5-1.1)$ & 0.073 \\
$\begin{array}{c}\text { (CI 95\%: } 1.1-2.3) \\
\quad \begin{array}{l}\text { hypertrophy } \\
\text { on ECG }\end{array}\end{array}$ & 2.4 & (CI 95\%: $1.8-3.0)$ & 0.028 \\
$\begin{array}{c}\text { K }<3.4 \text { mmol/L } \\
\text { Uric acid }>420 \\
\text { mmol/L }\end{array}$ & 1.4 & (CI 95\%: $1.1-1.7)$ & 0.021 \\
$\begin{array}{c}\text { eGFR }<50 \\
\text { BNP pg/L }\end{array}$ & 2.5 & (CI 95\%: $2.1-2.9)$ & 0.021 \\
\hline
\end{tabular}

Abbreviation: BNP: brain natriuretic peptide; eGFR: estimated glomerular filtration rate; $\mathrm{K}$ : potassium; BMS: body mass index.

the study for the developing of AF in patients with HF. After adjusting for age and sex multiple regression analysis showed positive predictive value for: history of hypertension of 1.6, history of DM of 1.4, for BMI $>28$

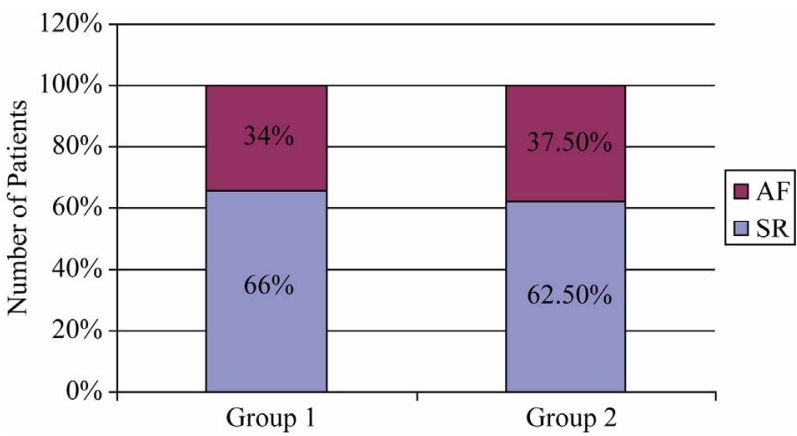

Figure 2. Distribution arial fibrillation $\mathrm{AF}, \mathrm{n}=\mathbf{7 6}$ and sinus rhythm $S R, n=148$ in group 1 , with diastolic heart failure and group 2, with systolic heart failure: $A F n=45$ and $S R$, $\mathrm{n}=\mathbf{7 5}$.

of 1.7, LVH on ECG of 2.

Biomarker positive predictors were hyperuricemia $>$ $420 \mathrm{mmol} / \mathrm{l}$ of 2.5 , higher BNP $>500 \mathrm{pg} / \mathrm{ml}$ of 3.8 , and low estimated glomerular filtration rate (eGFR) $<5$ of 2.1 , hypokalemia of $<3.4 \mathrm{mmol} / \mathrm{l}$ of 1.4 . Smoking was of negative predictive value.

\section{Discussion}

In this study patients with heart failure were evaluated with echocardiogram for segregation of those with systolic heart failure with reduced $\mathrm{EF}<50 \%$ from those 
who had DHF with LVEF $>50 \%$ and both were evaluated regarding the development of AF on ECG.

Patients with DHF compared with SHF had high female distribution and were older. This finding is similar to previous report, where $50 \%-70 \%$ of patients above the age of 70 had diastolic heart failure and $49 \%$ had systolic heart failure [9].

In this hospital based study with total of 7650 patients, the overall prevalence of heart failure over one year was $4.4 \%$. This was higher than other studies with prevalence of $4.1 \%$ and 4.2 respectively $[24,25]$.

The prevalence in of SHF was $1.8 \%$ and for DHF it was $2.3 \%$, which differ from one study by Mureddu GF et al., where the prevalence was $1.8 \%$ and $4.9 \%$ respectively with no difference by gender in patients with DHF [26].

The rate of occurrence of AF patients with HF in the study was of $35 \%$ which was higher than previous reports of $31 \%$ and $25 \%$ respectively [4,27]. The rate of occurrence of $\mathrm{AF}$ in both subgroups was nearly equal of $38 \%$ for SHF and of $37 \%$ in DHF.

In different clinical trials, the use of different diagnostic criteria and different age groups leads to variation of prevalence of HF. In one study by J. Grewal, et al., the prevalence of HF was $1.9 \%$ [28] and another study by S. J. Phillips et al., [29] the prevalence of HF was of $1.7 \%$. In both studies the prevalence was lower than this study although the prevalence was increasing as the patient's age increased.

Sixty eight percent of patients with DHF and AF were in severe diastolic dysfunction of restrictive pattern while $23 \%$ had mild dysfunction of abnormal relaxation pattern. This finding was in agreement with previous reports where severe diastolic dysfunction was associated with worse outcome including AF and mortality [30,31].

In previous studies women were less likely than men to have SHF accounting to $25 \%-35 \%$ of systolic heart failure cases [32]. In one report men have double the risk of developing blood-pumping (systolic) problems compared with women [33]. In this study percentage of female gender was higher in both DHF and SHF than male.

The age distribution for both groups showed increment in the rate of $\mathrm{HF}$ in old age patient, the percentage of DHF was two folds higher compared with SHF in young age patients but was equal in patients of $>65$ years. Patients of $>65$ years in SHF were twice higher than those of 50 - 65 years. In one study the estimated prevalence of diastolic dysfunction among patients with $\mathrm{HF}$ was 15,33 , and 50 percent at ages less than 50, $50-70$, and $>70$ years, respectively [34].

In one trial, a higher incidence of DHF occur in old age $<65$ years mainly due to ischemia and hypertension [35].
The level of BNP was significantly lower in those with DHF compared with SHF. This finding had been shown previously, where BNP was significantly high in SHF with no identifiable threshold to distinguish between the two forms of HF [28]. In one report higher level of BNP $>100 \mathrm{pg} / \mathrm{ml}$ was an independent predictor of adverse cardiovascular outcome in patients with DHF [36].

There was a significantly lower serum level of potassium in AF patients in patients with DHF but not in SHF. Previous studies showed AF is positively associated with hypokalemia [37].

In this study a higher rate of segmental wall motion abnormality on echo was detected in patients with $\mathrm{AF}$ both groups of HF.

The causative agents in DHF was mainly hypertension, followed by coronary artery disease while in SHF it was dilated myopathy followed valvular heart disease. In one reports by Topol et al., hypertension and ischemia were the main etiology of DHF [38].

In this study the best clinical predictors for development of AF in heart failure was the history of hypertension, followed by DM and obesity.

In patients with a SHF and dilated LV the heart failure, tachycardia-mediated cardiomyopathy was the presumed the causative agent in $29 \%$ of patients with HF however in this subset of patients improvement of function was seen with rhythm or rate control $[39,40]$.

\section{Limitation of the Study}

The echocardiographic findings were observed on admission and were not repeated after improvement of patient's clinical condition as tachycardia mediated HF cannot be ruled out as an etiological diagnosis on admission.

\section{REFERENCES}

[1] A. Mosterd, A. W. Hoes, M. C. de Bruyne, et al., "Prevalence of Heart Failure and Left Ventricular Dysfunction in the General Population; The Rotterdam Study," European Heart Journal, Vol. 20, No. 6, 1999, pp. 447-455. doi:10.1053/euhj.1998.1239

[2] J. P. Bounhoure, P. Massabuau, M. Galinier, et al., "[Heart Failure with Preserved Left Ventricular Function: Clinical, Echocardiographic, and Clinical Course Features. Prognostic Factors]," Bulletin de l'Academie Nationale de Medecine, Vol. 186, No. 6, 2002, pp. 1003-1014.

[3] R. Nagarakanti and M. Ezekowitz, "Diastolic Dysfunction and Atrial Fibrillation," Journal of Interventional Cardiac Electrophysiology, Vol. 22, No. 2, 2008, pp. 111-118. doi:10.1007/s10840-008-9203-8

[4] E. J. Benjamin, D. Levy, S. M. Vaziri, et al., "Independent Risk Factors for Atrial Fibrillation in a PopulationBased Cohort. The Framingham Heart Study," Journal of 
American Medical Association, Vol. 271, No. 11, 1994, pp. 840-844. doi:10.1001/jama.1994.03510350050036

[5] R. Nieuwlaat, L. W. Eurlings, J. G. Cleland, et al., "Atrial Fibrillation and Heart Failure in Cardiology Practice: Reciprocal Impact and Combined Management from the Perspective of Atrial Fibrillation: Results of the Euro Heart Survey on Atrial Fibrillation," Journal of the American College of Cardiology, Vol. 53, No. 18, 2009, pp. 1690-1698. doi:10.1016/j.jacc.2009.01.055

[6] J. G. Cleland, K. Swedberg, F. Follath, et al., "The EuroHeart Failure Survey Programme-A Survey on the Quality of Care among Patients with Heart Failure in Europe. Part 1: Patient Characteristics and Diagnosis," European Heart Journal, Vol. 24, No. 5, 2003, pp. 442463. doi:10.1016/S0195-668X(02)00823-0

[7] A. J. Camm and I. Savelieva, "Atrial Fibrillation: Advances and Perspectives," Dialogues in Cardiovascular Medicine, Vol. 8, 2003, pp. 183-202.

[8] M. Klapholz, M. Maurer, A. M. Lowe, et al., "Hospitalization for Heart Failure in the Presence of a Normal Left Ventricular Ejection Fraction: Results of the New York Heart Failure Registry," Journal of the American College of Cardiology, Vol. 43, No. 8, 2004, pp. 1432-1438. doi:10.1016/j.jacc.2003.11.040

[9] S. Yusuf, M. A. Pfeffer, K. Swedberg, et al., "Effects of Candesartan in Patients with Chronic Heart Failure and Preserved Left-Ventricular Ejection Fraction: The CHARMPreserved Trial," Lancet, Vol. 362, No. 9386, 2003, pp. 777-781. doi:10.1016/S0140-6736(03)14285-7

[10] M. M. Redfield, G. N. Kay, L. S. Jenkins, et al., "Tachycardia-Related Cardiomyopathy: A Common Cause of Ventricular Dysfunction in Patients with Atrial Fibrillation Referred for Atrioventricular Ablation," Mayo Clinic Proceedings, Vol. 75, No. 8, 2000, pp. 790-795. doi: $10.4065 / 75.8 .790$

[11] T. S. Tsang, B. J. Gersh, C. P. Appleton, et al., "Left Ventricular Diastolic Dysfunction as a Predictor of the First Diagnosed Nonvalvular Atrial Fibrillation in 840 Elderly Men and Women," Journal of American College of Cardiology, Vol. 40, No. 9, 2002, pp. 1636-1644. doi:10.1016/S0735-1097(02)02373-2

[12] R. S. Bhatia, J. V. Tu, D. S. Lee, et al., "Outcome of Heart Failure with Preserved Ejection Fraction in a Population-Based Study," New England Journal of Medicine, Vol. 355, No. 3, 2006, pp. 260-269. doi:10.1056/NEJMoa051530

[13] T. Fujino, T. Yamashita, S. Suzuki, et al., "Characteristics of Congestive Heart Failure Accompanied by Atrial Fibrillation with Special Reference to Tachycardia-Induced Cardiomyopathy," Circulation Journal, Vol. 71, No. 6, 2007, pp. 936-940. doi:10.1253/circj.71.936

[14] K. Dickstein, "Natriuretic Peptides in Detection of Heart Failure," Lancet, Vol. 351, No. 9095, 1998, pp. 9-13. doi:10.1016/S0140-6736(05)78100-9

[15] A. S. Maisel, P. Krishnaswamy, R. M. Nowak, et al., "Rapid Measurement of B-Type Natriuretic Peptide in the Emergency Diagnosis of Heart Failure," New England Journal of Medicine, Vol. 347, No. 3, 2002, pp. 161-167.

\section{doi:10.1056/NEJMoa020233}

[16] K. Dickstein, A. Cohen-Solal, G. Filippatos, et al., "ESC Guidelines for the Diagnosis and Treatment of Acute and Chronic Heart Failure 2008: The Task Force for the Diagnosis and Treatment of Acute and Chronic Heart Failure 2008 of the European Society of Cardiology. Developed in Collaboration with the Heart Failure Association of the ESC (HFA) and Endorsed by the European Society of Intensive Care Medicine (ESICM)," European Journal of Heart Failure, Vol. 10, No. 10, 2008, pp. 933-989. doi:10.1016/j.ejheart.2008.08.005

[17] P. Verdecchia, G. Schillaci, C. Borgioni, et al., "Prognostic Value of a New Electrocardiographic Method for Diagnosis of Left Ventricular Hypertrophy in Essential Hypertension," Journal of the American College of Cardiology, Vol. 31, No. 2, 1998, pp. 383-390. doi:10.1016/S0735-1097(97)00493-2

[18] A. S. Go, E. M. Hylek, K. A. Phillips, et al., "Prevalence of Diagnosed Atrial Fibrillation in Adults: National Implications for Rhythm Management and Stroke Prevention: The AnTicoagulation and Risk Factors in Atrial Fibrillation (ATRIA) Study," Journal of the American Medical Association, Vol. 285, No. 18, 2001, pp. 2370-2375. doi:10.1001/jama.285.18.2370

[19] D. J. Sahn, A. DeMaria, J. Kisslo, et al., "Recommendations Regarding Quantitation in M-Mode Echocardiography: Results of a Survey of Echocardiographic Measurements," Circulation, Vol. 58, No. 6, 1978, pp. 1072-1083. doi:10.1161/01.CIR.58.6.1072

[20] J. G. F. Cleland, E. Erdmann, R. Ferrari, et al., "Guidelines for the Diagnosis of Heart Failure," European Heart Journal, Vol. 16, 1995, p. 741.

[21] R. M. Lang, M. Bierig, R. B. Devereux, et al., "Recommendations for Chamber Quantification: A Report from the American Society of Echocardiography's Guidelines and Standards Committee and the Chamber Quantification Writing Group, Developed in Conjunction with the European Association of Echocardiography, a Branch of the European Society of Cardiology," Journal of the American Society of Echocardiography, Vol. 18, No. 12, 2005, pp. 1440-1463. doi:10.1016/j.echo.2005.10.005

[22] S. F. Nagueh, C. P. Appleton, T. C. Gillebert, et al., "Recommendations for the Evaluation of Left Ventricular Diastolic Function by Echocardiography," European Journal of Echocardiography, Vol. 10, No. 2, 2009, pp. 165193. doi:10.1093/ejechocard/jep007

[23] M. J. Koren, R. B. Devereux, P. N. Casale, et al., "Relation of Left Ventricular Mass and Geometry to Morbidity and Mortality in Uncomplicated Essential Hypertension," Annals of Internal Medicine, Vol. 114, No. 5, 1991, pp. 345-352.

[24] F. Ceia, C. Fonseca, T. Mota, et al., "Prevalence of Chronic Heart Failure in Southwestern Europe: The EPICA Study," European Journal of Heart Failure, Vol. 4, No. 4, 2002, pp. 531-539. doi:10.1016/S1388-9842(02)00034-X

[25] B. M. Massie and N. B. Shah, "Evolving Trends in the Epidemiologic Factors of Heart Failure: Rationale for 
Preventive Strategies and Comprehensive Disease Management," American Heart Journal, Vol. 133, No. 6, 1997, pp. 703-712. doi:10.1016/S0002-8703(97)70173-X

[26] G. F. Mureddu, N. Agabiti, V. Rizzello, et al., "Prevalence of Preclinical and Clinical Heart Failure in the Elderly. A Population-Based Study in Central Italy," European Journal of Heart Fail, Vol. 14, No. 7, 2012, pp. 718-729. doi:10.1093/eurjhf/hfs052

[27] J. G. Cleland, A. Khand and A. Clark, "The Heart Failure Epidemic: Exactly How Big Is It?" European Heart Journal, Vol. 22, No. 8, 2001, pp. 623-626. doi:10.1053/euhj.2000.2493

[28] J. Grewal, R. S. McKelvie, H. Persson, et al., "Usefulness of N-Terminal Pro-Brain Natriuretic Peptide and Brain Natriuretic Peptide to Predict Cardiovascular Outcomes in Patients with Heart Failure and Preserved Left Ventricular Ejection Fraction," American Journal of Cardiology, Vol. 102, No. 6, 2008, pp. 733-737. doi:10.1016/j.amjcard.2008.04.048

[29] S. J. Phillips, J. P. Whisnant, W. M. O'Fallon, et al., "Prevalence of Cardiovascular Disease and Diabetes Mellitus in Residents of Rochester, Minnesota," Mayo Clinic Proceedings, Vol. 65, No. 3, 1990, pp. 344-359. doi:10.1016/S0025-6196(12)62535-X

[30] T. A. McDonagh, C. E. Morrison, A. Lawrence, et al., "Symptomatic and Asymptomatic Left-Ventricular Systolic Dysfunction in an Urban Population," Lancet, Vol. 350, No. 9081, 1997, pp. 829-833. doi:10.1016/S0140-6736(97)03033-X

[31] J. E. Moller, E. Sondergaard, S. H. Poulsen, et al., "Pseudonormal and Restrictive Filling Patterns Predict Left Ventricular Dilation and Cardiac Death after a First Myocardial Infarction: A Serial Color M-Mode Doppler Echocardiographic Study," Journal of the American College of Cardiology, Vol. 36, No. 6, 2000, pp. 1841-1846. doi:10.1016/S0735-1097(00)00965-7

[32] F. Bursi, S. A. Weston, M. M. Redfield, et al., "Systolic and Diastolic Heart Failure in the Community," Journal of American Medical Association, Vol. 296, No. 18, 2006, pp. 2209-2216. doi:10.1001/jama.296.18.2209
[33] N. Ilksoy, M. Hoffman, R. H. Moore, et al., "Comparison of African-American Patients with Systolic Heart Failure versus Preserved Ejection Fraction," American Journal of Cardiology, Vol. 98, No. 6, 2006, pp. 806-808. doi:10.1016/j.amjcard.2006.03.066

[34] E. P. Havranek, F. A. Masoudi, K. A. Westfall, et al., "Spectrum of Heart Failure in Older Patients: Results from the National Heart Failure Project," American Heart Journal, Vol. 143, No. 3, 2002, pp. 412-417. doi: $10.1067 / \mathrm{mhj} .2002 .120773$

[35] J. I. Haft and L. E. Teichholz, "Echocardiographic and Clinical Risk Factors for Atrial Fibrillation in Hypertensive Patients with Ischemic Stroke," American Journal of Cardiology, Vol. 102, No. 10, 2008, pp. 1348-1351. doi:10.1016/j.amjcard.2008.07.009

[36] F. L. Dini, U. Conti, P. Fontanive, et al., "Prognostic Value of N-Terminal Pro-Type-B Natriuretic Peptide and Doppler Left Ventricular Diastolic Variables in Patients with Chronic Systolic Heart Failure Stabilized by Therapy," American Journal of Cardiology, Vol. 102, No. 4, 2008, pp. 463-468. doi:10.1016/j.amjcard.2008.03.083

[37] B. Al-Aloul, J. M. Li, D. Benditt, et al., "Atrial Fibrillation Associated with Hypokalemia Due to Primary Hyperaldosteronism (Conn's Syndrome)," Pacing and Clinical Electrophysiology, Vol. 29, No. 11, 2006, pp. 13031305. doi:10.1111/j.1540-8159.2006.00536.x

[38] E. J. Topol, T. A. Traill and N. J. Fortuin, "Hypertensive Hypertrophic Cardiomyopathy of the Elderly," New England Journal of Medicine, Vol. 312, No. 5, 1985, pp. 277-283. doi:10.1056/NEJM198501313120504

[39] M. A. Allessie, P. A. Boyden, A. J. Camm, et al., "Pathophysiology and Prevention of Atrial Fibrillation," Circulation, Vol. 103, No. 5, 2001, pp. 769-777. doi:10.1161/01.CIR.103.5.769

[40] J. S. Shinbane, M. A. Wood, D. N. Jensen, et al., "Tachycardia-Induced Cardiomyopathy: A Review of Animal Models and Clinical Studies," Journal of the American College of Cardiology, Vol. 29, No. 4, 1997, pp. 709-715. doi:10.1016/S0735-1097(96)00592-X 